\title{
Burden of Family Care-Givers and the Rationing in the Long Term Care Insurance Benefits of Japan
}

\author{
Tokyo Gakugei University \\ Wataru Suzuki \\ Hosei Institute on Aging \\ Seiritsu Ogura* \\ National Institute of Population and Social Security Research
}

Nobuyuki Izumida

\begin{abstract}
Long Term Care Insurance introduced in Japan in 2000 is rapidly turning into a system of rationed benefits due to financial difficulty. Based on our survey of 2500 family care-givers and the Zarit Care-Giver Burden Index, we have examined how these changes are affecting their subjective burden, following Kishida's seminary work. We have found evidence that (a)rationings in short-term-stays, day-services, or home-helper services, (b)disruptive or anti-social behaviors of the elderly, and (c)care-giver's own sleeping disorders are substantially adding to their burden. We have also found (d)a causal relationship where a higher burden is resulting in poor self-reported health.
\end{abstract}

\section{JEL Classification: $\quad$ I18 I19 H31}

\footnotetext{
* Corresponding Author

E-mail: sogura@hosei.ac.jp Tel: +81-3-3264-9091 Fax:+81 -3-3264-5764
}

We would like to thank Professor Sooman Kwon of Seoul National University and Professor Kensaku Kishida for helpful comments. The earlier version of this paper was presented at the International Symposium on Aging on November15, 2006, at School of Public Health, Seoul National University, and Japan Economic Association Meetings on October 2006. The research was supported by a research grant from the Ministry of Health, Labor and Welfare (Microeconometrics of Lifestyle, Health and Health Care Consumption), a Special Grant of Ministry of Education, Science and Technology, to Hosei Institute on Aging in 2005, and a Grant-in Aid for Scientific Research from Ministry of Education, Science and Technology to Hitotsubashi University on Economic Analysis of Intergenerational Issues. 
Key Words: Long-term Care Insurance, Burden Index of Care-Givers, Rationning 


\section{Introduction}

The Care-Giver Burden Index proposed by Zarit (1990), hereafter ZCBI, has been intensively studies in such fields as nursing, gerontology, social welfare, and geriatric medicine, but, until very recently, economics has remained an exception. This does not seem to be simply a Japanese phenomenon, but a universal one. Actually, the one exception we could find is the unpublished work of Kishida and Tanigaki (2004), hereafter KT. As they have made clear in their seminary work on the shortcomings of Long-Term Care Insurance of Japan (LTCI), the ZCBI has a lot to offer to economists and policy-makers. Recently, more and more economists have started to work with indices of subjective wellbeing, particularly in the field of Happiness Study or Happiness Research ${ }^{1}$. For quite some time, health economists have been working with such indices in the field of mental health ${ }^{2}$ or in quality of life adjustment problems. Through these researches, economics has been accumulating substantial body of theoretical and statistical knowledge regarding these indices of subjective wellbeing.

Few economists therefore should be surprised if we started using another subjective index of wellbeing in our empirical works on long term care: one may even say that such a research is overdue in the field. Furthermore, for several reasons, Caregiver's Burden Index is an invaluable analytical tool in evaluating the LTCI of Japan.

First of all, in evaluating the performance of LTCI, particularly in at-home care, we should be primarily concerned about the wellbeing of family caregivers. One of the

\footnotetext{
${ }^{1}$ For a comprehensive introduction, please refer to Frey and Stutzer(2002), Layard(2005),Van Praag and Ferrer-I-Carbonell(2004). An example in health economics is Gruber and Mullainathan(2002).

${ }^{2}$ For example, Frank and Manning(1992),Wildman(2003), Hauck and Rice(2004).
} 
most important reasons why Japan needed LTCI, the government had argued and we had agreed then, was to relieve the excessive burden of the family care-givers. Characterized as "Long-Term Care-Giver's Hell", the excessive burden frequently drove them to abuses of the elderly, and sometimes, even to murders or murder-suicides of caregivers and the cared elderly. It is therefore surprising to find, during the six years after the introduction of LTCI, only a small number of researches on this subject: a study of Cabinet Office (2002) and two papers by Shimizutani and Noguchi (2004 and 2005) are notable exceptions. All these researches relied, however, on the time spent for caring the elderly as the measure of the care-giver's burden. In fact, they have found out that there had been very little change before and after the introduction of $\mathrm{LTCI}^{3}$. In gerontology, Sugisawa et al(2005) have reached a similar conclusion using pre-LTCI and post-LTCI data from Mitaka-city, a suburb of Tokyo ${ }^{4}$

In the second place, ZCBI is superior to time for cares as a measure of caregiver's burden for two reasons; one negative and the other positive. On the negative side, as $\mathrm{KT}(2004)$ emphasize, time spent for cares is an imperfect proxy of the burden because (a)the distinction between the regular housework and the cares is sometime very blurry, and (b)the intensity of care per unit time can have a large variance, from low-intensity cares of watching or sleeping in the same room, to high-intensity at-home nursing cares. Furthermore (c) Tsusui (2004) points out that self-reported time for

\footnotetext{
${ }^{3}$ For example, Cabinet-Office(2002) has found that, compared with 1999, (1) the proportion of households where the main family-caregivers spend more than 8 hours a day has decreased very little, from $21.7 \%$ to $20.5 \%$, and (2) the average time spent by the main family care-givers has decreased from 5.4 hours to 5.2 hours in their data.

${ }^{4}$ Sugisawa et al (2005) have compared the two surveys, one conducted in 1998 and another in 2002, and found that, while there is a noticeable reduction in the proportion of households in which main family care-givers " provide care everyday, but nonexclusively" from $58.0 \%$ to $49.5 \%$, the proportion of family care-givers who "provide care everyday exclusively" has decreased very little, from $25.0 \%$ to $24.2 \%$. They have also found that only $6 \%$ utilize home-helpers in families that have one or more elderly with light ADL deficiency but medium to serious dementia, and that the rate has actually decreased after the introduction of LTCI.
} 
cares deviates very substantially from the time observed by researchers. On the positive side, unlike time for cares, ZCBI score is a direct measurement of the burden, and many studies in the last decade have established the effectiveness of ZCBI as a consistent measure of care-giver's burden. Thus it is more appropriate to use CBI which is a direct measure rather than the using the time for care as a proxy ${ }^{5}$.

Thirdly, unlike the time for care, ZBCI score offers an analytical framework to evaluate the quality or quantity of LTCI benefits. In particular, it can even show where new benefits of LTCI are needed to relieve the burden: this is precisely what KT (2004) have tried to show6. They regressed the Japanese ZCBI scores on four groups of factors: namely, (a)properties of the elderly, (b)properties of the caregivers, (c)the "conditions of care", and (d)the factors restricting LTCI benefits. They found out, among other things, that dementia of the elderly, animosity between the care-givers and the elderly, night-time cares needs, insufficient use of short-term stay, and poorly constructed care-plans add to the burden of the family caregivers, and propose a number of improvements in the LTCI.

In what follows, we try to do the following; namely, we adopt KT's basic research strategy and we focus our attention to the increasing rationing problems in LTCI to find out how they are affecting the family care-givers. We will evaluate quantitatively which rationings are particularly hurting the caregiver's wellbeing, or what new benefits are needed most. There are some important differences, however, between KT and our study: first is the difference in geographical scope. Our samples are

\footnotetext{
5 In the fields of Social Welfare and gerontology, we note that, in addition to Sugisawa et al (2005), Kuwahara et at (2002) and Washio et al (2002) had tried this approach before. Unfortunately, due to very small sample sizes as well as other technical problems, their reported results are far from conclusive.

6 The original paper of Kishida and Tanigaki (2004) has not been published yet, but the reader is referred to Kishida (2005) for a digest version of the paper.
} 
national, whereas Kishida and Tanigaki's are from two rural prefectures in the western part of Japan? ${ }^{7}$ Since LTCI programs are run by municipal governments, theoretically, this difference can be very important. If we obtain similar results to theirs, more generality can be claimed to these conclusions. Second difference is in the Zarit index. Here we have used a shorter (8 questions) version of ZBIC, while KT(2004) used its full (22 questions) version. If a shorter version works well, it can lower the survey costs substantially. Third difference is in the treatment of subjective health: we have paid special attention to the interdependency of the poor self-reported health and high ZBCI scores, which KT interpreted as one-way causal relatioship.

Our findings can be summarized as follows: As KT reported, we can confirm that (a) rationing in major LTCI benefits, (b)anti-social behaviors or animosity of the elderly directed toward the caregiver, and (c)sleeping disorders of the caregivers do add to the burden of family caregivers. Unlike KT, however, we have found that (d) a substantial part of the positive correlation between poor health and higher burden comes from the latter causing the former. These four findings, we believe, indicate the need for additional dimensions in the LTCI benefit structure, including the psychological care of the caregivers. Lastly, we are happy to report that a shorter Japanese version of ZBIC seems to work just as well.

\section{Data}

\subsection{Nature of Our Data}

The data used in this paper was obtained through an internet survey of households with some long term care needs. The survey questions were developed by the authors,

\footnotetext{
7 They collected data through interviews, in two cities of Chugoku-district of Japan, of households with at least one member who needs long-term care and waiting for the admission to public nursing homes.
} 
but the internet survey was conducted by a national marketing service company on their panel of "monitor" households during the period of March 9 through March 13. Specifically, the company has selected 4000 individuals above the age 16 who are living with someone needing long term care, and asked them to reply to our internet survey. The number of responding individual altogether was 2714, a response rate of $67.9 \%$. For our present paper, we have excluded the families with more than 2 members needing long term care, resulting in a sample of 2530 households.

The Zarit Burden Index of Caregivers, or ZBIC, is one of the standard measures of the subjective burden of care givers (Zarit et al(1980), Zarit et al(1991)). It provides a comprehensive measurement of physical, psychological and economic burdens of long term care in a single index. The full ZBIC is computed from 22 individual questions, and the Japanese version is provided by Dr.Yumiko Arai of National Institute of Longevity Sciences of Japan. In this paper, however, we have used an 8 question version of the ZBIC, JZBI8, developed also by Dr.Arai and her associates (Arai et al 2003), primarily to secure better response rates in our internet survey. The following are the eight questions. As answers, the respondents are asked to choose one of the four alternatives (never, seldom, sometimes, often, always). These answers are given fixed weights of $(0,1,2,3,4)$ respectively and the J-ZBI-8 score is computed as the sum. The maximum score of the J-ZBI- 8 is therefore 32 .

\section{J-ZBI-8 Questions}

Q1 I am embarrassed by the behaviors of the cared person.

Q2 I am irritated when I am near the cared person

Q3 I have less communication with my family or with my friends due to my care-giving. 
Q4 I lose the peace of my mind when I am near the cared person.

Q5 I have lost social participation due to my care-giving responsibility.

Q6 I cannot invite my friends to my home since the cared person is there.

Q7 I want someone to take the caring responsibility off my shoulder.

Q8 I don't know how to deal with the cared person.

In Table 1, we have listed the descriptive statistics of our sample. In judging the quality of our dataset, however, it is important for us to compare the characteristics of our sample households with the larger national survey of households providing long term care conducted by the Ministry of Health, Labor and Welfare, or MHLW. In the first place, there is a distinct bias in the age distribution of the caregivers in our sample. In Table 2 we have shown the age distribution of the caregivers of our samples: compared with the MHLW samples, our caregivers are clearly younger. This happens because an internet survey still selectively limits the participation of older generation due to the differential internet accessibility and literacy. In the second place, however, there are no systematic biases in the care-need grade distribution between our sample and MHLW sample as we can see in Table 3. Even though our sample contains larger proportions of grade 1 and grade 5, it seems to mimic the MHLW national sample fairly well. In the third place, as is clear in Table 4, we note that our caregivers are generally healthier in terms of self-reported health, which may explain part of the result we have obtained in this paper.

\subsection{Time and Burden of Care-Givers}

In most of the policy-reviews of the Ministry of Health, Labor and Welfare, time for 
cares has been used as the proxy for the subjective burden of the care-givers. Let us examine the relationship between these two variables in our samples: Figure 1 is the scatter diagram of the time spent for cares and the burden index of the caregivers (J-ZBI-8). While we can observe a weak positive correlation $(\rho=0.1837)$ between these two variables, the relationship is subject to fairly large errors, far from being a close one. Thus relying on time for care as the sole proxy for caregiver's burden can be misleading 8

\subsection{Proxies for LTCI Benefits}

We want to discuss our data on the rationing aspect of LTCI benefits. In our questionnaire, for each of the LTCI benefits, we have asked the caregivers the number of hours/days each service was provided and the desired number of hours/days for the service. We define the difference between the desired values and the actual values as the "gap" values, which stands for the result of rationing. In Table 5, we summarize the number of hours/days of services were provided and their desired number of hours/days. We can observe there are positive gaps in all the services, but the largest gap can be found in short-term stays. In fact, while actual number of days the service was provided was only 2.96 , the desired number of days was 6.02 , or more than twice the actual benefit.

Our Table 6 measures the satisfaction levels for quality and quantity of LTCI benefits. We will treat the dissatisfaction as an index of quality rationing, by constructing dummy variables for selecting either "dissatisfied" or "very dissatisfied" for each benefit. In the table, short-term-stay leads the list of dissatisfaction, followed

\footnotetext{
${ }^{8}$ Suzuki, one of the present authors, has confirmed the same result using J-ZBI, instead of J-ZBI-8 (Cabinet Office 2006).
} 
by home-helper services and in-facility rehabilitations.

\section{Analysis of BIC function}

\subsection{Specification}

In order to see how these gaps in LTCI benefits are affecting the burden of family care givers, we specify the BIC as a function of the gaps and all other control variables that can affect the caregiver's burden and estimate the equation given by

$$
Y=X \alpha+Z \beta+\varepsilon
$$

In the equation (1) Y stands for the value of J-ZBI-8, and X stands for the vector of "gaps" in LTCI benefits obtained by subtracting the number of hours/days each service was provided from the desired number of hours/days, and "dissatisfaction index" for the LTCI benefits.

The vector $\mathrm{Z}$ stands for all other factors that can affect the caregiver's burden: the first group of factors consists of dummy variables of such characteristics of the cared individual as the sex, age, LTCI need class grade(from 0 to 4), and various anti-social behaviors (reversal of night and day, rude words and violent behaviors, screaming, resisting to cares, roaming, inability to find home, mismanagement of fire, going out alone, unsanitary behaviors, eating disorders, syndrome of self-injury, ingratitude, open hostility to you).

The second group of factors in $\mathrm{Z}$ consists of the distributive nature of the family care: the amount of time spent for care by the surveyed individual, cooperation of the family members including spouse, children, other members living together, or other relatives living elsewhere, etc.

The third group of factors in $\mathrm{Z}$ consists of the care-givers characteristics, the sex, 
age, education, number of individuals in the family, living in owner-occupied houses or not, log of household income, health status, having any sleeping problems ${ }^{9}$ etc..

We should note three things in this specification: In the first place, if we have a perfect insurance coverage in our LTCI, caregiver's burden scores will be the same, regardless of the care need grades, characteristics of the cared elderly, or their own: none of these variables should have a statistically significant coefficient. In other words, a significant coefficient in these variables suggests an incompleteness or insufficiency in the structure of LTCI benefits.

In the second place, it is well-known that the present Japanese LTCI provides little extra benefits for the elderly who exhibit these anti-social behaviors, and it does not adjust the benefits, at least formally, to personal conditions of the family caregivers. It is therefore natural for us to expect that these factors make a large difference in the burden of the family care-givers under normal circumstances. One can interpret these variables standing for the incompleteness of present LTCI insurance benefits.

In the third place, this specification does not include the utilization levels of LTCI benefits. We assume they are determined by their care-managers as a function of Care Need Grade, and their effects are collectively captured in the coefficients of each Care Need Grade dummy variable. If the care-plans are made optimally for each Care Need Grade, then individual benefits should not matter.

In the fourth place, however, if the care-plans are suboptimal, the distances between the optimal and the actual levels are the sources of inefficiency and they

\footnotetext{
${ }^{9}$ If the surveyed individuals selected one or more symptoms out of the four (insufficient hours of sleep, difficulty in falling asleep, frequent interruption by the elderly, and light sleep), this dummy variable is set to 1 , otherwise its value is zero.
} 
should be included in the regression. We shall call these distances or difference as "gaps" in LTCI benefits, including the absence of LTCI benefits. As they are the sources of inefficiency, they should be included in the regression ${ }^{10}$.

\subsection{Baseline Estimation Result}

Our Model 1 in Table 7 shows the baseline estimation under our present specification. The dummy variables for each LTCI need level have significant coefficients, but the value is rising until care need reaches 3 , after which it falls. Qualitatively, this result is consistent with the finding of Kishida and Tanigaki (2004), who placed their peak at Grade 4. Our result suggests that LTCI benefits are not sufficient for those with LTCI care need $3^{11}$. For problem behaviors, we can see that not only particular behaviors as "rude words and behaviors", "screaming", "resisting to care", "roaming", "going out alone", "unsanitary behaviors", more general attitudes as "ingratitude" and "hostility" as felt by the family caregivers, seem to influence the BIC substantially. In particular, it is quite noteworthy that "ingratitude" alone raises the BIC score by more than 4 points.

While the coefficient of time spent for caring is statistically significant, the magnitude of its marginal effect is of rather modest, equal to an increase of 0.82 point in BIC score for a 10 hour increase.

For our gap variables, those of home-helper service, day-service, and short-term-stay are statistically significant: rationing in these services tends to increase BIC scores. As to the quality dissatisfaction index indicating they were

${ }^{10}$ We will check the endogeneity problem of these Gap variables in 4.2.

${ }^{11}$ As Care Need Grade goes up, the family is entitled to a larger budget, and the care-manager is usually willing to release more benefits to the elderly. This may partially explain the lower BIC score for higher end Care Need Scores. 
either dissatisfied or very dissatisfied, only for the home-helper service, it has a significant positive sign.

Family cooperation in the care is also an important element in BIC determination: BIC score is reduced when the caregiver's children or other family members in the same household contribute to the care of the elderly.

On the other hand, household income has a significant negative sign: higher the household income, the lower is the burden of the family care giver.

Lastly, the health of the family caregiver seems to be important: BIC score increases when the self-evaluated health is poor or bad, or as the number of physical discomforts increases. Also, when the caregivers are suffering from sleeping problems, their BIC scores increase substantially. How to secure the family caregivers sufficient amount of sleep during the night is a problem that has not been fully addressed in the present LTCI benefits ${ }^{12}$.

\subsection{Estimation Result with ADL Variables}

In the previous estimation, one may worry about the quality of the LTCI Care Need Grade as a control of the physical status of the cared elderly: it may suffer from regional biases or selection biases inherent in the administrative process of the LTCI that is initiated by application. For this reason, in Model 2 of Table 7, we have used individual ADL dummy variables instead of the Care Need Grades. These ADL dummy variables are set to zero when no disability is involved. In this result, the gap variables and health variables are significant, confirming the robustness of our basic

12 In Kishida and Tanigaki (2004), this problem probably explains their counter-intuitive results regarding the night-time care variables: they have found that availability of nighttime care adds substantially to the Z-BIC score. 
model.

In Model 3 of Table 8, we have crossed our gap variables with Care Need Grade variable, and tried to identify the particular Care Need Grade where BIC scores are sensitive to the gap variables. Significant coefficients were obtained for day-service and short-term-stay for Care Need Grade 1 or less, home-helper and short-term-stay services for Care Need Grade 2 and 3, as well as day-service for Care Need Grade 4 and 5. We can conclude that rationing of short-stay service for low and middle Care Need Grade family is seriously adding to the family care-giver's burden. Other results are roughly identical to those in Model 1 of Table 7, confirming again the robustness of our result.

In Table 8 (Model 4), we examined if the BIC scores of caregivers in low-income family are differentially affected by these gaps: in particular, we wanted to find out if the out-of-pocket cost is keeping them from using the LTCI benefits, and increasing their burden score. For this purpose, we have crossed low-income dummy variable (household income less than 3,000,000 yen) with our gap variables, and added them to the regressors. Our results in the table show that the only significant coefficient was obtained for home-nursing, but, for such LTIC benefits for which gap variables were significant, as home-helper, day-service, and short-term-stay, the low-income households were not different from other households.

In Table 9, we have examined the relationship between the gap variables and the household income class. While we observe larger gaps in home-nursing for the low-income households, the difference between the two income classes seem to be modest in other services, including day-service and short-term-stay. 


\section{Endogeneity Problem}

\subsection{Endogeneity in care-givers' health}

Our results so far (Mode 1 through Model 4) have consistently indicated that the poor or bad self-reported health of the care-givers adds to their subjective burden. While this result is consistent with the Kishida-Tanigaki's, however, we felt that we should worry about the endogeneity problem in the self-reported health of care-givers: it is very likely that a higher subjective burden may result in poorer self-evaluated health.

In order to cope with this problem, in Table 10 (Model 5), we have treated the "poor or bad" health variable as an endogenous variable and 12 chronic diseases dummies as the instruments: they are (1)Hypertension etc (2)Heart Diseases (3)Diabetes etc (4)Strokes etc (5)Gastritis etc (6)Asthma, Bronchitis (7)Rheumatism (8)Glacoma and Cataract (9)Kidney Diseases (10)Hemorrhoid (11)Alzheimer's (12)Depression.

We have assumed in this specification that most of these diseases had predated the start of the care-giving, and hence these dummies are theoretically independent of the ZBIC. As a precaution, we have estimated the poor or bad health equation and ZBIC equation using these chronic disease dummies as explanatory variables. Most of chronic disease dummies have significant coefficients in poor or bad health equation, but none were significant in ZBIC equation, confirming our expectation.

Our IV regression result in Table10 (Model 5) now shows that poor or bad health is no longer statistically significant. On the other hand, in IV regression of the poor or bad health equation in Table 11, ZBIC is statistically significant ${ }^{13}$. Through these analyses, we can conclude that the OLS results of Model 1 through Model 4, are

13 We have treated ZBIC as an endogenous variable and 6 Gap variables as the instruments. 
generated, not by the poor or bad health causing higher burden, but rather by the higher burden causing the poor or bad health. On the one hand, this is a natural result: recently, Ogura (2006) has found that self-reported health of Japanese workers reflects closely their psychological stress, and for family care-givers, care-giving is probably the most important source of their everyday stress. On the other hand, it may indicate a possibility of data truncation: if a caregiver has experienced a very serious deterioration of health, the family member who needed long term care may have been already moved to an institutional care facility. Another possibility is that our result may be driven by the generally younger caregivers (Table 2) who enjoy relatively good health (Table 4). Given these possibilities, we want to simply point out that a substantial part of the positive correlation between higher subjective burden and poor or bad health is due to the endogeneity problem in the subjective health.

\subsection{Endogeneity in Gap Variables}

Finally, we want to address ourselves to the possible endogeneity problem of our Gap variables. These variables have been obtained as the difference between the actual LTCI benefits and the quantities desired by caregivers. The result of Wu-Hausman test on this specification is shown in Table 10 (Model 6). As none of the residuals of the Gap variables are significant, we can assume that the endogeneity problem for the Gap variables is not serious.

\section{Concluding Remarks}

In this paper, we have examined the factors that determine the burden of the family care-givers. Based on own national internet survey of 2500 individual family 
care-givers, we have examined how the rationing in the benefits, as well as the absence of coverage, in LTCI are adding to the ZBIC scores of family care-givers. Particularly, we have found out that apparent rationings in three important services, namely, short-term-stay, day-service, and home-helpers, raise the ZBIC scores significantly. We have also found out that dissatisfaction in the home-nursing care service contributes to the BIC score. Furthermore, when anti-social behaviors or animosity toward the care-givers are present, or if the care-givers are experiencing sleeping problems, ZBIC scores increase substantially. In sum, we have to conclude that present LTCI benefits fail to address to the some of the most important needs of the caring family, either in quantity or in scope. A systematic attempt has to be made to remove or reduce these factors.

As to the relationship between the poor health and the burden of the caregivers, we have shown that a higher burden is contributing to the deterioration subjective health in our sample. Whether or not poor health adds to the burden is not clear in our sample of relatively young and healthier carregivers. In any case, policy intervention is clearly called for to sustain the mental health of family caregivers, as caregivers seem to be coping with their burden through unhealthy habits, which will reduce their health even further. 


\section{Reference}

Arai Y, et al(1997), "Reliability and validity of the Japanese version of the Zarit Caregiver Burden Interview.” Psychiatry Clin Neurosci 51, pp.281-287

Arai Y, et al(2003) "Kaigo futan shakudo nihongo-ban no tanshuku-ban no sakusei (Formulation of the Japanese shorter version of the Zarit Caregiver Burden Interview: investigation of its reliability and validity; in Japanese)" Nihon Rounen Igakku-kai Zashi(Japanese Journal of Geriatrics) 40(5), pp.471-477

Cabinet Office(2002) Kaigo sabisu sijou no issou no kourituka no tameni (pursuit of further efficiency in long-term care service market; in Japanese), Kaigo sabisu kakaku ni kansuru kenkyukai Hokokusho (Research report of study group on long-term care price)

Cabinet Office(2006) Zaitaku kaigo no genjou to kaigo hoken seido no minaoshi ni kansuru chosa (present situation of the at-home care and reexamination of Japanese LTCI; in Japanese), Seisaku Bunseki Report No.21 (Policy Analysis Research Report)

Frank, R and W. Manning, Jr.(1992), Economics and Mental Health, The Johns Hopkins University Press

Frey, B. and Stutzer, A.(2002) "What can economist learn from Happiness Research?", Journal of Economic Literature 40, pp.402-435

Gruber, J .and Mullainathan, S.(2002) "Do cigarette taxes make smokers happier?"Advances in Economic Analysis and Policy 5(1) (Article 4) 
Hauck, K. and N. Rice.(2004) "A longitudinal analysis of mental health mobility in Britain” Health Economics 13, pp.981-1001

Kishida,K and S. Tanigaki ( 2004 ) "Zaitaku sabisu nani ga tarinai-noka? Kazoku-kaigosha no kaigo-futankan no bunseki (What's needed in at-home service? An analysis of family-care burden; in Japanese)" paper presented in 4th iryo-keizaigaku kaigi(4th Japanese research conference on health economics in Kyoto)

Kishida,K ( 2005 ) "Zaitaku sabisu nani ga tarinai noka? Kazoku-kaigosha no kaigo-futankan no bunseki (What's needed in at-home service? An analysis of family-care burden; in Japanese)" Shukan shakai hosho(weekly journal of social security) No. 2352.

Layard, R (2005), Happiness: Lessons from a new science, The Penguin Press, NewYork

Ogura, S (2006) "Stress to Kenko no Jikohyoka to iryouhi no kankei nit suite (Relationship between Stress, Self-reported Health and Healthcare Cost; in Japanese)" Iryo Keizai Kenkyu(Japanese Journal of Health Economics \& Policy ) Vol.18 No.1

Shimizutani, S., and Noguchi, H.,(2004) Kaigo hoiku service shijou no keizai bunseki-micro-data niyoru jittai kaimei to seisaku teigen (an economic analysis on the elderly and child care in Japan: micoro-level investigation with policy implication; in Japanese) Toyo keizai shinpo sha, Tokyo

Shimizutani, S., and Noguchi, H.,(2005) "Chokikan Kaigo ha naze kaisho shinainoka? (What Accounts for the Onerous Care Burden at Home in Japan? 
Evidence from Household Data;in Japanese)" Keizai Bunseki(Economic Analysis)No.175, pp. 1-32.

Sugisawa,H., Y,Nakatani and Y,Sugihara(2005) Kaigo hoken seido no hyoka (Policy Evaluation of Japanese long-term care insurance) Miwa Shobo, Tokyo

Tsutsui, T (2004) Koreishakai no kea saiensu(Care science in an aging society) Chuohoki, Tokyo

Van Praag, B and A Ferrer-I-Carbonell(2004) Happiness Quantified: A Satisfaction Calculus Approach, Oxford University Press

Washio, M. et al(2003), "Kaigohoken donyu ichinengo niokeru Fukuoka-ken Enga-chiku no yokaigosha wo kaigosuru kazoku no kaigo futankan(Clinical assessment of microscopic polyangiities in elderly patients)" Nihon Ronen Igaku-kai Zashi((Japanese Journal of Geriatrics) Vol.40(2), pp.147-155

Wildman,J(2003) "Income inequalities in mental health in Great Britain: Analysing the causes of health inequality over time." Journal of Health Economics 22, pp.295-312

Zarit S H, et al(1980), "Relatives of the impaired elderly: Correlates of feelings of burden" Gerontologist 20, pp.649-655

Zarit S H, et al(1990), "The memory and behaviour problems checklist 1987R and the burden interview.” Pennsylvania State University Gerontology Center: University Park, PA 
Figure 1 J-ZBI-8 and Time for Care of the Care-givers

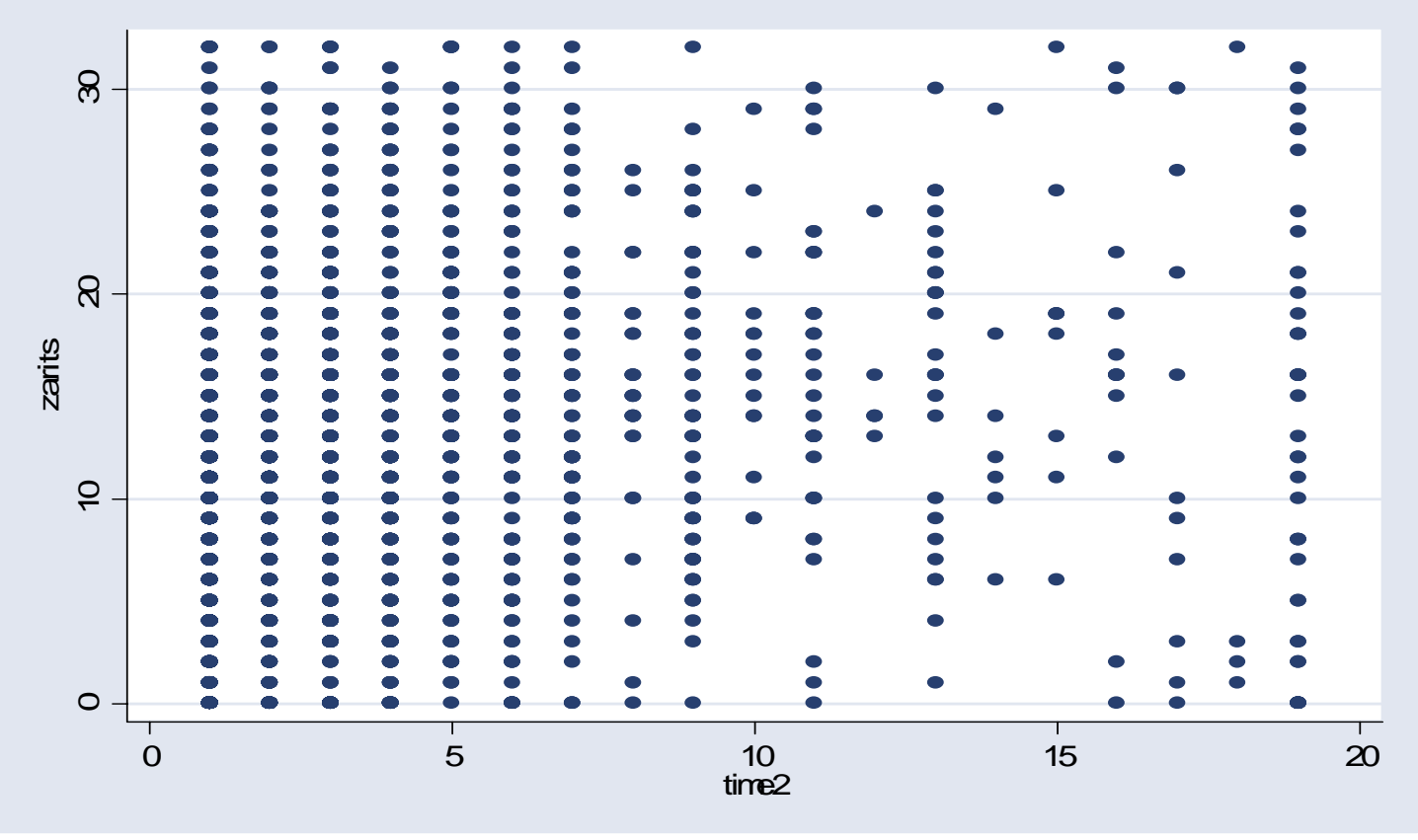


Table 1 Descriptive Statistics

\begin{tabular}{|c|c|c|c|c|c|}
\hline Variable Names* & Sample Size & Means & SD & Min & Max \\
\hline$\overline{\text { CE:J-ZBI-8 Score }}$ & 2530 & 11.9075 & 7.5692 & 0 & 32 \\
\hline CE:Male Elderly & 2530 & 0.3249 & 0.4684 & 0 & 1 \\
\hline CE :Age & 2530 & 78.3972 & 9.7427 & 65 & 100 \\
\hline CE :Independent & 2530 & 0.0379 & 0.1911 & 0 & 1 \\
\hline CE Sppor $t$ & 2530 & 0.1190 & 0.3238 & 0 & 1 \\
\hline CE:Grade1 & 2530 & 0.1794 & 0.3838 & 0 & 1 \\
\hline CE:Grade2 & 2530 & 0.1601 & 0.3668 & 0 & 1 \\
\hline CE:Grade3 & 2530 & 0.1447 & 0.3518 & 0 & 1 \\
\hline CE:Grade4 & 2530 & 0.0972 & 0.2963 & 0 & 1 \\
\hline CE:Grade5 & 2530 & 0.0960 & 0.2947 & 0 & 1 \\
\hline CE:No Certification & 2530 & 0.1656 & 0.3718 & 0 & 1 \\
\hline CE:TD in Brushing Teeth & 2530 & 0.1779 & 0.3825 & 0 & 1 \\
\hline CE:PH in Brushing Teeth & 2530 & 0.2676 & 0.4428 & 0 & 1 \\
\hline CE:TD in Dressing & 2530 & 0.2095 & 0.4070 & 0 & 1 \\
\hline CE:PH in Dressing & 2530 & 0.4119 & 0.4923 & 0 & 1 \\
\hline CE:TD in Eating & 2530 & 0.1364 & 0.3432 & 0 & 1 \\
\hline CE:PH in Eating & 2530 & 0.3881 & 0.4874 & 0 & 1 \\
\hline CE:TD in Toilets & 2530 & 0.2063 & 0.4047 & 0 & 1 \\
\hline CE:PH in Toilets & 2530 & 0.3020 & 0.4592 & 0 & 1 \\
\hline CE:TD in Bathing & 2530 & 0.3636 & 0.4811 & 0 & 1 \\
\hline CE:PH in Bathing & 2530 & 0.3783 & 0.4850 & 0 & 1 \\
\hline CE:TD in Walking & 2530 & 0.2387 & 0.4264 & 0 & 1 \\
\hline CE:PH in Walking & 2530 & 0.5095 & 0.5000 & 0 & 1 \\
\hline CE:Unable to Communicate & 2530 & 0.0767 & 0.2661 & 0 & 1 \\
\hline PB:N\&D Revarsal & 2530 & 0.1909 & 0.3931 & 0 & 1 \\
\hline PB:Rude W\&D & 2530 & 0.1111 & 0.3143 & 0 & 1 \\
\hline PB:Screaming & 2530 & 0.1320 & 0.3386 & 0.0000 & 1 \\
\hline PB:Resisting & 2530 & 0.1395 & 0.3466 & 0 & 1 \\
\hline PB:Roaming & 2530 & 0.0711 & 0.2571 & 0 & 1 \\
\hline PB:Unable to Come Home & 2530 & 0.0715 & 0.2578 & 0 & 1 \\
\hline PB:Mistreating Fire & 2530 & 0.1051 & 0.3068 & 0 & 1 \\
\hline PB:Going Out Alone & 2530 & 0.1150 & 0.3191 & 0 & 1 \\
\hline PB:Unsanitary Habits & 2530 & 0.1431 & 0.3502 & 0 & 1 \\
\hline PB:Eating Disorders & 2530 & 0.1075 & 0.3098 & 0 & 1 \\
\hline PB:Self-Inflicting Woonds & 2530 & 0.0217 & 0.1459 & 0 & 1 \\
\hline PB:No Gratitude & 2530 & 0.1866 & 0.3896 & 0 & 1 \\
\hline PB:Animosity & 2530 & 0.1040 & 0.3053 & 0 & 1 \\
\hline T:Time by CG & 2530 & 3.5375 & 3.5923 & 1 & 19 \\
\hline Gap:Home Helper & 2530 & 1.5194 & 4.3899 & -13 & 41 \\
\hline Gap:Home Bathing & 2530 & 0.9498 & 3.0237 & -29 & 31 \\
\hline Gap:Home Nursing & 2530 & 0.8419 & 3.1399 & -31 & 31 \\
\hline Gap:Rehabilitation & 2530 & 1.3735 & 3.8796 & -8 & 31 \\
\hline Gap:Day Service & 2530 & 1.9459 & 4.5794 & -16 & 31 \\
\hline Gap:Short-Term Stay & 2530 & 3.0601 & 6.7127 & -31 & 31 \\
\hline US:Home Helper & 2530 & 0.0368 & 0.1882 & 0 & 1 \\
\hline US:Home Bathing & 2530 & 0.0154 & 0.1232 & 0 & 1 \\
\hline US:Home Nursing & 2530 & 0.0154 & 0.1232 & 0 & 1 \\
\hline US:Rehabilitation & 2530 & 0.0352 & 0.1843 & 0 & 1 \\
\hline US:Day Service & 2530 & 0.0427 & 0.2022 & 0 & 1 \\
\hline DU:Short-Term Stay & 2530 & 0.0415 & 0.1995 & 0 & 1 \\
\hline FC:Spouse & 2530 & 0.3142 & 0.4643 & 0 & 1 \\
\hline FC:Children & 2530 & 0.1107 & 0.3138 & 0 & 1 \\
\hline FC:Other Family & 2530 & 0.4589 & 0.4984 & 0 & 1 \\
\hline FC:Relatives & 2530 & 0.1142 & 0.3182 & 0 & 1 \\
\hline FC:No FC & 2530 & 0.1822 & 0.3861 & 0 & 1 \\
\hline CG:Male & 2530 & 0.4613 & 0.4986 & 0 & 1 \\
\hline CG:Age & 2530 & 41.7184 & 11.3786 & 20 & 80 \\
\hline CG:College or more & 2530 & 0.3542 & 0.4783 & 0 & 1 \\
\hline CG:Family Size & 2530 & 3.0632 & 1.5052 & 1 & 10 \\
\hline CG:Owner-Occupied House & 2530 & 0.8727 & 0.3333 & 0 & 1 \\
\hline CG:Income & 2232 & 672.5806 & 396.7409 & 200 & 2000 \\
\hline CG:log(income) & 2232 & 6.3461 & 0.5809 & 5.298317 & 7.600903 \\
\hline CG:Sleeping Problems & 2530 & 0.7134 & 0.4522 & 0 & 1 \\
\hline CG:Poor and Bad Health & 2530 & 0.2241 & 0.4171 & 0 & 1 \\
\hline
\end{tabular}


Table2 Age Distribution of Family Care-Giver

\begin{tabular}{|c|c|c|}
\hline & Our Survey & MHLW Survey \\
\hline Under 30s & $5.7 \%$ & $0.9 \%$ \\
\hline $30 \mathrm{~s}$ & $26.4 \%$ & $2.9 \%$ \\
\hline $40 \mathrm{~s}$ & $30.9 \%$ & $13.4 \%$ \\
\hline $50 \mathrm{~s}$ & $22.9 \%$ & $31.1 \%$ \\
\hline $60 \mathrm{~s}$ & $11.9 \%$ & $26.1 \%$ \\
\hline $70 \mathrm{~s}$ & $1.9 \%$ & $19.3 \%$ \\
\hline Over $80 \mathrm{~s}$ & $0.2 \%$ & $6.4 \%$ \\
\hline
\end{tabular}

Ministry of Health, Labour and Welfare(2000) "Household Survey of Family Care-Givers"

Table3 Distribution of the Care Need Grades

\begin{tabular}{|c|c|c|}
\hline & Our Survey & MHLW Survey \\
\hline Sppor t & $21.3 \%$ & $16.4 \%$ \\
\hline Grade1 & $19.0 \%$ & $32.5 \%$ \\
\hline Grade2 & $17.2 \%$ & $14.9 \%$ \\
\hline Grade3 & $11.5 \%$ & $12.8 \%$ \\
\hline Grade4 & $11.4 \%$ & $12.1 \%$ \\
\hline Grade5 & $19.6 \%$ & $11.3 \%$ \\
\hline
\end{tabular}

Ministry of Health, Labour and Welfare(2004) "Business Report on LTCI"

Table4 Self-Reported Health

\begin{tabular}{|c|c|c|}
\hline & Our Survey & MHLW Survey \\
\hline Good & $14.2 \%$ & $18.2 \%$ \\
\hline Fair & $22.8 \%$ & $14.5 \%$ \\
\hline Neutral & $40.5 \%$ & $37.7 \%$ \\
\hline Poor & $19.6 \%$ & $25.8 \%$ \\
\hline Bad & $2.8 \%$ & $3.7 \%$ \\
\hline
\end{tabular}

Ministry of Health, Labour and Welfare(2000) "Household Survey of Family Care-Givers" 
Table 5 Gaps in LTCI Benefits: What Care-giverss Want vs What They Actually Get

\begin{tabular}{lllllll}
\hline & & Means & & SD & Min & Max \\
\hline Home Helper & Days Wanted & 2.18 & 5.2096 & 0 & 41 \\
& Days Provided & 3.70 & 7.4757 & 0 & 41 \\
Home Bathing & Days Wanted & 0.92 & 2.8983 & 0 & 31 \\
& Days Provided & 1.87 & 4.4079 & 0 & 31 \\
Home Nursing & Days Wanted & 1.05 & 3.3786 & 0 & 31 \\
Rehabilitaion & Days Provided & 1.89 & 4.7629 & 0 & 31 \\
& Days Wanted & 1.73 & 3.9792 & 0 & 31 \\
Day Service & Days Provided & 3.10 & 5.7441 & 0 & 31 \\
& Days Wanted & 4.05 & 6.0477 & 0 & 31 \\
Short Term Stay & Days Provided & 6.00 & 7.8470 & 0 & 31 \\
& Days Wanted* & 2.96 & 7.6957 & 0 & 31 \\
& Days Provided* & 6.02 & 10.0454 & 0 & 31 \\
\hline All figures are for
\end{tabular}

All figures are for one month, except for short- term stay which is for 6 months.

Table 6 LTCI Benefits Quality Judged by Caregivers

\begin{tabular}{|l|r|r|r|r|r|r|}
\hline & Home Helper & $\begin{array}{c}\text { Home } \\
\text { Batthing }\end{array}$ & $\begin{array}{c}\text { Home } \\
\text { Nursing }\end{array}$ & $\begin{array}{c}\text { Rehabilitati } \\
\text { on }\end{array}$ & Day Service & $\begin{array}{c}\text { Short Term } \\
\text { Stay }\end{array}$ \\
\hline Very Satisfied & 8.2 & 14.1 & 12.1 & 7.8 & 12.1 & 11.2 \\
\hline Satisfied & 36.8 & 42.6 & 34.9 & 33.7 & 41.3 & 33.1 \\
\hline Neutral & 42.7 & 33.2 & 44.2 & 44.8 & 36.8 & 36.4 \\
\hline Unsatified & 8.8 & 7.6 & 6.6 & 10.9 & 7.5 & 15.4 \\
\hline Very Unsatisfied & 3.6 & 2.6 & 2.3 & 2.8 & 2.3 & 3.9 \\
\hline
\end{tabular}

Table 9 Household Income and LTCI Benefit GAPs

\begin{tabular}{|c|c|c|c|c|c|c|}
\hline Household Income & Homehelper & $\begin{array}{c}\text { Home } \\
\text { Bathing }\end{array}$ & $\begin{array}{c}\text { Home } \\
\text { Nursing }\end{array}$ & Rehabilitation & Day Service & Short Term Stay \\
\hline $\begin{array}{c}\text { Less Than 3million } \\
\text { Yen }\end{array}$ & 1.59 & 0.91 & 0.91 & 1.35 & 1.85 & 2.66 \\
\hline $\begin{array}{c}3 \text { million }<<6 \\
\text { million }\end{array}$ & 1.45 & 1.04 & 0.78 & 1.46 & 1.89 & 3.01 \\
\hline $\begin{array}{c}6 \text { million }<<10 \\
\text { million }\end{array}$ & 1.19 & 0.75 & 0.82 & 1.18 & 2.15 & 3.07 \\
\hline 10 million $<$ & 1.49 & 0.78 & 0.79 & 1.25 & 1.93 & 2.93 \\
\hline
\end{tabular}


Table 7 Baseline OLS Estimation of J-ZBIC-8 Function

\begin{tabular}{|c|c|c|c|c|c|c|}
\hline \multirow[b]{2}{*}{ Variables } & \multicolumn{3}{|c|}{ Model 1(Baseline OLS) } & \multicolumn{3}{|c|}{$\underline{\text { Model2(OLS) }}$} \\
\hline & Coeff & & SE & Coeff & & SE \\
\hline CE:Male Elderly & 0.4951 & * & 0.2788 & 0.4519 & & 0.2840 \\
\hline CE :Age & 0.0151 & & 0.0143 & 0.0206 & & 0.0141 \\
\hline CE Sppor $t$ & 1.6254 & ** & 0.6610 & - & & \\
\hline CE:Grade1 & 2.6837 & $* * *$ & 0.6416 & - & & \\
\hline CE:Grade2 & 3.2584 & $* * *$ & 0.6519 & - & & \\
\hline CE:Grade3 & 3.4579 & $* * *$ & 0.6633 & - & & \\
\hline CE:Grade4 & 3.1924 & $* * *$ & 0.7148 & - & & \\
\hline CE:Grade5 & 2.7111 & $* * *$ & 0.7108 & - & & \\
\hline CE:No Certification & 1.9342 & $* * *$ & 0.6548 & - & & \\
\hline CE:TD in Brushing Teeth & - & & & -0.7289 & & 0.6758 \\
\hline CE:PH in Brushing Teeth & - & & & 0.0244 & & 0.3709 \\
\hline CE:TD in Dressing & - & & & -0.1511 & & 0.6624 \\
\hline CE:PH in Dressing & - & & & 0.8513 & ** & 0.3564 \\
\hline CE:TD in Eating & - & & & 0.2041 & & 0.5975 \\
\hline CE:PH in Eating & - & & & 0.7635 & ** & 0.3070 \\
\hline CE:TD in Toilets & - & & & 1.6048 & ** & 0.6542 \\
\hline CE:PH in Toilets & 一 & & & 0.5356 & & 0.3676 \\
\hline CE:TD in Bathing & - & & & 0.8176 & * & 0.4952 \\
\hline CE:PH in Bathing & - & & & -0.1771 & & 0.3579 \\
\hline CE:TD in Walking & - & & & -0.5500 & & 0.5515 \\
\hline CE:PH in Walking & - & & & 0.1220 & & 0.3232 \\
\hline CE:Unable to Communicate & - & & & -0.6943 & & 0.5450 \\
\hline PB:N\&D Revarsal & 0.3929 & & 0.3598 & 0.3703 & & 0.3610 \\
\hline PB:Rude W\&D & 0.9809 & * & 0.5356 & 1.0509 & $* *$ & 0.5359 \\
\hline PB:Screaming & 0.9506 & $* *$ & 0.4143 & 0.8813 & $* *$ & 0.4250 \\
\hline PB:Resisting & 1.5970 & $* * *$ & 0.4069 & 1.4517 & $* *$ & 0.4092 \\
\hline PB:Roaming & 1.1698 & $* *$ & 0.5770 & 1.1940 & $* *$ & 0.5802 \\
\hline PB:Unable to Come Home & 0.6831 & & 0.5403 & 0.6873 & & 0.5638 \\
\hline PB:Mistreating Fire & 0.6231 & & 0.4516 & 0.6219 & & 0.4497 \\
\hline PB:Going Out Alone & 0.7976 & $*$ & 0.4124 & 0.7403 & $*$ & 0.4114 \\
\hline PB:Unsanitary Habits & 1.8121 & $* * *$ & 0.4158 & 1.6870 & $* *$ & 0.4200 \\
\hline PB:Eating Disorders & 0.3019 & & 0.4392 & 0.2718 & & 0.4422 \\
\hline PB:Self-Inflicting Woonds & -0.8068 & & 0.8815 & -0.9794 & & 0.8891 \\
\hline PB:No Gratitude & 4.5809 & $* * *$ & 0.3819 & 4.6002 & $* *$ & 0.3835 \\
\hline PB:Animosity & 1.5337 & $* * *$ & 0.4882 & 1.5187 & $* * *$ & 0.4861 \\
\hline $\mathrm{T}:$ Time by CG & 0.0815 & $*$ & 0.0453 & 0.0588 & & 0.0473 \\
\hline Gap:Home Helper & 0.1139 & $* * *$ & 0.0382 & 0.1159 & $* * *$ & 0.0391 \\
\hline Gap:Home Bathing & -0.0079 & & 0.0486 & -0.0343 & & 0.0493 \\
\hline Gap:Home Nursing & 0.0134 & & 0.0528 & 0.0039 & & 0.0522 \\
\hline Gap:Rehabilitation & -0.0289 & & 0.0402 & -0.0294 & & 0.0402 \\
\hline Gap:Day Service & 0.1072 & $* * *$ & 0.0379 & 0.1221 & $* * *$ & 0.0383 \\
\hline Gap:Short-Term Stay & 0.1423 & $* * *$ & 0.0236 & 0.1437 & $* * *$ & 0.0235 \\
\hline US:Home Helper & 2.6757 & $* * *$ & 0.8353 & 2.8228 & $* * *$ & 0.8129 \\
\hline US:Home Bathing & 0.8386 & & 1.2183 & 0.6838 & & 1.1537 \\
\hline US:Home Nursing & -0.5209 & & 1.2545 & -0.5179 & & 1.2339 \\
\hline US:Rehabilitation & -0.1156 & & 0.6824 & -0.1102 & & 0.6914 \\
\hline US:Day Service & 0.3074 & & 0.6371 & 0.4450 & & 0.6399 \\
\hline US:Short-Term Stay & -0.2765 & & 0.6512 & -0.4784 & & 0.6547 \\
\hline FC:Spouse & 0.2508 & & 0.3262 & 0.2187 & & 0.3302 \\
\hline FC:Children & -1.2070 & $* * *$ & 0.4360 & -1.1884 & $* * *$ & 0.4403 \\
\hline FC:Other Family & -1.3203 & $* * *$ & 0.3348 & -1.2980 & $* * *$ & 0.3421 \\
\hline FC:Relatives & -0.0993 & & 0.4207 & 0.0367 & & 0.4192 \\
\hline CG:Male & -1.4824 & $* * *$ & 0.2783 & -1.5068 & $* * *$ & 0.2800 \\
\hline CG:Age & 0.0236 & $*$ & 0.0135 & 0.0318 & $* *$ & 0.0134 \\
\hline CG:College or more & 0.5921 & $* *$ & 0.2743 & 0.6050 & $* *$ & 0.2723 \\
\hline CG:Family Size & 0.1529 & & 0.1036 & 0.1211 & & 0.1028 \\
\hline CG:Owner-Occupied House & 0.9676 & $* *$ & 0.3897 & 0.9580 & $* *$ & 0.3849 \\
\hline CG:log(income) & -0.5523 & ** & 0.2379 & -0.5704 & $* *$ & 0.2403 \\
\hline CG:Sleeping Problems & 1.6793 & $* * *$ & 0.2821 & 1.6863 & $* * *$ & 0.2833 \\
\hline CG:Poor and Bad Health & 1.1873 & $* * *$ & 0.3216 & 1.1585 & $* * *$ & 0.3209 \\
\hline Constant & 5.6066 & $* * *$ & 1.8543 & 6.6378 & $* * *$ & 1.8119 \\
\hline Number of observation & 2,232 & & & 2,232 & & \\
\hline R-squared & 0.4268 & & & 0.4309 & & \\
\hline
\end{tabular}


Table 8 J-ZBIC-8 Function with Crossed Gap Variables

\begin{tabular}{|c|c|c|c|c|c|c|}
\hline \multirow[b]{2}{*}{ Variables } & \multicolumn{3}{|c|}{$\underline{\text { Model3(OLS) }}$} & \multicolumn{3}{|c|}{ Model4(OLS) } \\
\hline & Coeff & & SE & Coeff & & SE \\
\hline $\begin{array}{l}\text { CE:Male Elderly } \\
\text {. }\end{array}$ & 0.5134 & * & 0.2807 & 0.5094 & * & 0.2791 \\
\hline CE :Age & 0.0162 & & 0.0145 & 0.0165 & & 0.0143 \\
\hline CE Sppor t & 1.4037 & $* *$ & 0.6755 & 1.6250 & $* *$ & 0.6608 \\
\hline CE:Grade1 & 2.3700 & *** & 0.6657 & 2.6750 & $* * *$ & 0.6414 \\
\hline CE:Grade2 & 3.3207 & *** & 0.6709 & 3.2357 & $* * *$ & 0.6514 \\
\hline CE:Grade3 & 3.5051 & **** & 0.6791 & 3.4382 & $* * *$ & 0.6632 \\
\hline CE:Grade4 & 3.2054 & **** & 0.7543 & 3.1841 & $* * *$ & 0.7164 \\
\hline CE:Grade5 & 2.7260 & $* * *$ & 0.7334 & 2.7092 & $* * *$ & 0.7110 \\
\hline CE:No Certification & 2.3702 & $* * *$ & 0.6663 & 1.9457 & $* * *$ & 0.6553 \\
\hline PB:N\&D Revarsal & 0.3507 & & 0.3633 & 0.4141 & & 0.3604 \\
\hline PB:Rude W\&D & 0.9968 & * & 0.5385 & 0.9940 & $*$ & 0.5403 \\
\hline PB:Screaming & 1.0244 & $* *$ & 0.4156 & 0.9877 & $* *$ & 0.4169 \\
\hline PB:Resisting & 1.6213 & *** & 0.4114 & 1.5664 & $* * *$ & 0.4069 \\
\hline PB:Roaming & 1.1521 & ** & 0.5864 & 1.1535 & * & 0.5806 \\
\hline PB:Unable to Come Home & 0.6458 & & 0.5556 & 0.6525 & & 0.5426 \\
\hline PB:Mistreating Fire & 0.6846 & & 0.4587 & 0.6057 & & 0.4520 \\
\hline PB:Going Out Alone & 0.7483 & * & 0.4151 & 0.7900 & $*$ & 0.4136 \\
\hline PB:Unsanitary Habits & 1.6990 & *** & 0.4232 & 1.8438 & $* * *$ & 0.4176 \\
\hline PB:Eating Disorders & 0.4053 & & 0.4478 & 0.2919 & & 0.4421 \\
\hline PB:Self-Inflicting Woonds & -0.5333 & & 0.8967 & -0.8682 & & 0.8873 \\
\hline PB:No Gratitude & 4.5884 & $* * *$ & 0.3814 & 4.5754 & $* * *$ & 0.3826 \\
\hline PB:Animosity & 1.5520 & **** & 0.4938 & 1.4909 & $* * *$ & 0.4915 \\
\hline T:Time by CG & 0.0792 & * & 0.0458 & 0.0841 & * & 0.0456 \\
\hline Gap:Home Helper in Low Care Grades & 0.1149 & & 0.0990 & - & & \\
\hline Gap:Home Bathing in Low Care Grades & -0.0229 & & 0.1172 & - & & \\
\hline Gap:Home Nursing in Low Care Grades & -0.1246 & & 0.1142 & - & & \\
\hline Gap:Rehabilitation in Low Care Grades & 0.0589 & & 0.0723 & - & & \\
\hline Gap:Day Service in Low Care Grades & 0.1122 & * & 0.0577 & - & & \\
\hline Gap:Short-Term Stay in Low Care Grades & 0.2079 & $* * *$ & 0.0470 & - & & \\
\hline Gap:Home Helper in Middle Care Grades & 0.1130 & ** & 0.0571 & - & & \\
\hline Gap:Home Bathing in Middle Care Grades & 0.0074 & & 0.0631 & - & & \\
\hline Gap:Home Nursing in Middle Care Grades & 0.1020 & & 0.0957 & - & & \\
\hline Gap:Rehabilitation in Middle Care Grades & -0.1213 & * & 0.0733 & - & & \\
\hline Gap:Day Service in Middle Care Grades & 0.0273 & & 0.0603 & - & & \\
\hline Gap:Short-Term Stay in Middle Care Grades & 0.1590 & $* * *$ & 0.0318 & - & & \\
\hline Gap:Home Helper in High Care Grades & 0.0753 & & 0.0837 & - & & \\
\hline Gap:Home Bathing in High Care Grades & -0.1313 & & 0.1070 & - & & \\
\hline Gap:Home Nursing in High Care Grades & 0.0599 & & 0.0730 & - & & \\
\hline Gap:Rehabilitation in High Care Grades & -0.0067 & & 0.0747 & - & & \\
\hline Gap:Day Service in High Care Grades & 0.2634 & *** & 0.0881 & - & & \\
\hline Gap:Short-Term Stay in High Care Grades & 0.0593 & & 0.0450 & - & & \\
\hline Gap:Home Helper & - & & & 0.1209 & $* * *$ & 0.0411 \\
\hline Gap:Home Bathing & - & & & 0.0198 & & 0.0509 \\
\hline Gap:Home Nursing & - & & & -0.0444 & & 0.0608 \\
\hline Gap:Rehabilitation & - & & & -0.0475 & & 0.0441 \\
\hline Gap:Day Service & - & & & 0.1088 & $* * *$ & 0.0416 \\
\hline Gap:Short-Term Stay & - & & & 0.1571 & $* * *$ & 0.0244 \\
\hline Gap:Home Helper in Low Income & - & & & -0.0076 & & 0.1076 \\
\hline Gap:Home Bathing in Low Income & - & & & -0.1272 & & 0.1254 \\
\hline Gap:Home Nursing in Low Income & - & & & 0.1805 & * & 0.1055 \\
\hline Gap:Rehabilitation in Low Income & - & & & 0.0564 & & 0.0981 \\
\hline Gap:Day Service in Low Income & - & & & 0.0121 & & 0.0934 \\
\hline Gap:Short-Term Stay in Low Incoem & - & & & -0.0906 & & 0.0701 \\
\hline US:Home Helper & 2.7042 & $* * *$ & 0.8482 & 2.6912 & $* * *$ & 0.8303 \\
\hline US:Home Bathing & 0.8163 & & 1.1792 & 0.8757 & & 1.2077 \\
\hline US:Home Nursing & -0.4434 & & 1.2069 & -0.5067 & & 1.2500 \\
\hline US:Rehabilitation & -0.0356 & & 0.6877 & -0.1505 & & 0.6753 \\
\hline US:Day Service & 0.1021 & & 0.6379 & 0.3738 & & 0.6426 \\
\hline US:Short-Term Stay & -0.0684 & & 0.6572 & -0.2649 & & 0.6491 \\
\hline FC:Spouse & 0.2731 & & 0.3260 & 0.2764 & & 0.3269 \\
\hline FC:Children & -1.1687 & $* * *$ & 0.4400 & -1.1989 & $* * *$ & 0.4369 \\
\hline FC:Other Family & -1.2865 & $* * *$ & 0.3349 & -1.3096 & $* * *$ & 0.3349 \\
\hline FC:Relatives & -0.0598 & & 0.4252 & -0.0989 & & 0.4214 \\
\hline CG:Male & -1.5250 & *** & 0.2811 & -1.4806 & $* * *$ & 0.2793 \\
\hline CG:Age & 0.0226 & * & 0.0135 & 0.0239 & * & 0.0135 \\
\hline CG:College or more & 0.6887 & $* *$ & 0.2765 & 0.5922 & $* *$ & 0.2750 \\
\hline CG:Family Size & 0.1502 & & 0.1042 & 0.1458 & & 0.1041 \\
\hline CG:Owner-Occupied House & 0.9596 & *** & 0.3922 & 0.9480 & ** & 0.3889 \\
\hline CG:log(income) & -0.5583 & $* *$ & 0.2404 & -0.5984 & ** & 0.2490 \\
\hline CG:Sleeping Problems & 1.7014 & $* * *$ & 0.2832 & 1.6863 & $* * *$ & 0.2819 \\
\hline CG:Poor and Bad Health & 1.2794 & $* * *$ & 0.3255 & 1.2013 & $* * *$ & 0.3217 \\
\hline Constant & 5.6445 & $* * *$ & 1.8682 & 5.7938 & $* * *$ & 1.9093 \\
\hline Number of observation & 2,232 & & & 2,232 & & \\
\hline R-squared & 0.4238 & & & 0.4286 & & \\
\hline
\end{tabular}


Table 10 IV 2SLS Estimation of J-ZBIC-8 Function

\begin{tabular}{|c|c|c|c|c|c|c|}
\hline \multirow[b]{2}{*}{ Variables } & \multicolumn{3}{|c|}{$\underline{\text { Model5(IV 2SLS) }}$} & \multicolumn{3}{|c|}{$\underline{\text { Model6(IV 2SLS) }}$} \\
\hline & Coeff & & SE & Coeff & & SE \\
\hline CE:Male Elderly & 0.4833 & * & 0.2806 & 0.9444 & * & 0.4960 \\
\hline CE :Age & 0.0138 & & 0.0144 & 0.0248 & & 0.0225 \\
\hline CE :Sppor $t$ & 1.6080 & $* *$ & 0.6651 & 1.4343 & $* *$ & 0.6739 \\
\hline CE:Grade1 & 2.6752 & $* * *$ & 0.6449 & 2.3451 & $* * *$ & 0.6627 \\
\hline CE:Grade2 & 3.2233 & $* * *$ & 0.6568 & 2.7084 & $* * *$ & 0.6906 \\
\hline CE:Grade3 & 3.4259 & $* * *$ & 0.6683 & 2.7101 & $* * *$ & 0.7090 \\
\hline CE:Grade4 & 3.1629 & $* * *$ & 0.7212 & 2.3989 & $* * *$ & 0.7757 \\
\hline CE:Grade5 & 2.6849 & $* * *$ & 0.7166 & 1.8319 & $* *$ & 0.8001 \\
\hline CE:No Certification & 1.9258 & $* * *$ & 0.6578 & 1.5875 & $* *$ & 0.6743 \\
\hline PB:N\&D Revarsal & 0.3947 & & 0.3610 & 0.3526 & & 0.3627 \\
\hline PB:Rude W\&D & 0.9958 & $*$ & 0.5383 & 1.0511 & $*$ & 0.5398 \\
\hline PB:Screaming & 0.9705 & $* *$ & 0.4165 & 0.9167 & $* *$ & 0.4233 \\
\hline PB:Resisting & 1.6247 & $* * *$ & 0.4094 & 1.5028 & $* *$ & 0.4108 \\
\hline PB:Roaming & 1.1465 & $* *$ & 0.5790 & 1.1432 & $*$ & 0.5864 \\
\hline PB:Unable to Come Home & 0.6813 & & 0.5373 & 0.5995 & & 0.5576 \\
\hline PB:Mistreating Fire & 0.6163 & & 0.4509 & 0.6149 & & 0.4506 \\
\hline PB:Going Out Alone & 0.8780 & $* *$ & 0.4194 & 0.8795 & $* *$ & 0.4220 \\
\hline PB:Unsanitary Habits & 1.8532 & $* * *$ & 0.4195 & 1.7682 & $* * *$ & 0.4199 \\
\hline PB:Eating Disorders & 0.2933 & & 0.4409 & 0.2537 & & 0.4416 \\
\hline PB:Self-Inflicting Woonds & -0.7531 & & 0.8766 & -0.8526 & & 0.8789 \\
\hline PB:No Gratitude & 4.6183 & $* * *$ & 0.3883 & 4.5997 & $* * *$ & 0.3894 \\
\hline PB:Animosity & 1.5396 & $* * *$ & 0.4892 & 1.5755 & $* * *$ & 0.4908 \\
\hline $\mathrm{T}$ :Time by CG & 0.0839 & $*$ & 0.0457 & 0.0573 & & 0.0466 \\
\hline Gap:Home Helper & 0.1174 & $* * *$ & 0.0388 & 0.2999 & & 0.4171 \\
\hline Gap:Home Bathing & -0.0061 & & 0.0488 & -0.4645 & & 0.6559 \\
\hline Gap:Home Nursing & 0.0138 & & 0.0534 & 1.6249 & & 1.0075 \\
\hline Gap:Rehabilitation & -0.0244 & & 0.0403 & 0.0215 & & 0.4893 \\
\hline Gap:Day Service & 0.1061 & $* * *$ & 0.0381 & -0.7540 & & 0.6092 \\
\hline Gap:Short-Term Stay & 0.1430 & $* * *$ & 0.0236 & 0.6200 & $*$ & 0.3180 \\
\hline Residual:Home Helper & - & & & -0.1827 & & 0.4221 \\
\hline Residual:Home Bathing & 一 & & & 0.4380 & & 0.6575 \\
\hline Residual:Home Nursing & 一 & & & -1.6121 & & 1.0051 \\
\hline Residual:Rehabilitation & - & & & -0.0492 & & 0.4900 \\
\hline Residual:Day Service & - & & & 0.8682 & & 0.6097 \\
\hline Residual:Short-Term Stay & - & & & -0.4828 & & 0.3176 \\
\hline US:Home Helper & 2.7621 & $* * *$ & 0.8418 & 2.7364 & $* * *$ & 0.8275 \\
\hline US:Home Bathing & 0.8824 & & 1.2178 & 0.7886 & & 1.2130 \\
\hline US:Home Nursing & -0.5452 & & 1.2692 & -0.6839 & & 1.2598 \\
\hline US:Rehabilitation & -0.1253 & & 0.6887 & -0.0601 & & 0.6867 \\
\hline US:Day Service & 0.3379 & & 0.6429 & 0.3744 & & 0.6407 \\
\hline US:Short-Term Stay & -0.2720 & & 0.6552 & -0.4619 & & 0.6503 \\
\hline FC:Spouse & 0.2143 & & 0.3306 & 0.1645 & & 0.3336 \\
\hline FC:Children & -1.2295 & $* * *$ & 0.4397 & -1.2650 & $* * *$ & 0.4400 \\
\hline FC:Other Family & -1.3186 & $* * *$ & 0.3352 & -1.3625 & $* * *$ & 0.3387 \\
\hline FC:Relatives & -0.0730 & & 0.4188 & -0.0728 & & 0.4197 \\
\hline CG:Male & -1.4983 & $* * *$ & 0.2799 & -1.5256 & $* * *$ & 0.2798 \\
\hline CG:Age & 0.0267 & $*$ & 0.0142 & 0.0289 & $* *$ & 0.0141 \\
\hline CG:College or more & 0.5389 & $*$ & 0.2801 & 0.5527 & $* *$ & 0.2789 \\
\hline CG:Family Size & 0.1439 & & 0.1046 & 0.1244 & & 0.1042 \\
\hline CG:Owner-Occupied House & 0.9399 & ** & 0.3890 & 0.8904 & $* *$ & 0.3888 \\
\hline CG:log(income) & -0.5990 & $* *$ & 0.2473 & -0.5958 & ** & 0.2475 \\
\hline CG:Sleeping Problems & 1.7874 & $* * *$ & 0.3112 & 1.7965 & $* * *$ & 0.3122 \\
\hline CG:Poor and Bad Health & 0.4063 & & 1.0338 & 0.3629 & & 1.0355 \\
\hline Constant & 6.0307 & $* * *$ & 1.9487 & 4.6360 & $*$ & 2.3837 \\
\hline Number of observation & 2,232 & & & 2,232 & & \\
\hline R-squared & 0.4252 & & & 0.4297 & & \\
\hline
\end{tabular}

*** significant at the 1 percent level.

** significant at the 5 percent level.

* significant at the 10 percent level.

Notes: Gap function is based on the following equation:

Gap $=\beta_{0}+\beta_{1}{ }^{*} \mathrm{CE}$ :Male Elderly $+\beta_{2}{ }^{*} \mathrm{CE}:$ Age $+\beta_{3}{ }^{*} \mathrm{CE}$ :TD in Brushing Teeth $+\beta_{4}{ }^{*} \mathrm{CE}: \mathrm{PH}$ in Brushing Teeth $+\beta_{5}{ }^{*} \mathrm{CE}: \mathrm{TD}$ in Dressing $+\beta_{6}{ }^{*} \mathrm{CE}: \mathrm{PH}$ in Dressing $+\beta_{7}{ }^{*} \mathrm{CE}: \mathrm{TD}$ in Eating $+\beta_{8}{ }^{*} \mathrm{CE}: \mathrm{TD}$ in Eating $+\beta_{9}{ }^{*} \mathrm{CE}$ :TD in Toilets $+\beta_{10}{ }^{*} \mathrm{CE}: \mathrm{PH}$ in Toilets $+\beta_{11}{ }^{*} \mathrm{CE}:$ TD in Bathing $+\beta_{12}{ }^{*} \mathrm{CE}: \mathrm{PH}$ in Bathing $+\beta_{13}{ }^{*} \mathrm{CE}$ :TD in Walking $+\beta_{14}{ }^{*} \mathrm{CE}: \mathrm{PH}$ in Walking $+\beta_{15}{ }^{*} \mathrm{CE}:$ Unable to Communicate $+u$

Instrument variables for Poor and Bad Health is Individual Chronic Diseases dummies: (1)Hypertension and Others (2)Heart Diseases (3)Diabetes and Others (4)Strokes and Others

(5)Gastritis and Others (6)Asthma, Bronchitis (7)Rheumatism (8)Glacoma and Cataract (9)Kidney Diseases (10)Hemorrhoid (11)Alzheimer's (12)Depression 
Table 11 IV Probit Estimation of Poor and Bad Health Function

\begin{tabular}{|c|c|c|c|}
\hline \multirow[b]{2}{*}{ Variables } & \multicolumn{3}{|c|}{ IV Probit } \\
\hline & Coeff & & $\mathrm{SE}$ \\
\hline CE:Male Elderly & -0.0929 & & 0.0762 \\
\hline CE :Age & -0.0049 & & 0.0040 \\
\hline CE :Sppor t & -0.0360 & & 0.2095 \\
\hline CE:Grade1 & 0.0255 & & 0.2083 \\
\hline CE:Grade2 & -0.1654 & & 0.2189 \\
\hline CE:Grade3 & -0.1118 & & 0.2220 \\
\hline CE:Grade4 & -0.0861 & & 0.2300 \\
\hline CE:Grade5 & -0.0155 & & 0.2230 \\
\hline CE:No Certification & 0.0585 & & 0.2027 \\
\hline PB:N\&D Revarsal & 0.0346 & & 0.0934 \\
\hline PB:Rude W\&D & -0.0811 & & 0.1275 \\
\hline PB:Screaming & 0.1189 & & 0.1091 \\
\hline PB:Resisting & -0.0586 & & 0.1125 \\
\hline PB:Roaming & -0.3039 & $*$ & 0.1557 \\
\hline PB:Unable to Come Home & -0.0339 & & 0.1369 \\
\hline PB:Mistreating Fire & -0.0179 & & 0.1190 \\
\hline PB:Going Out Alone & 0.1879 & $*$ & 0.1070 \\
\hline PB:Unsanitary Habits & 0.0142 & & 0.1124 \\
\hline PB:Eating Disorders & -0.0536 & & 0.1138 \\
\hline PB:Self-Inflicting Woonds & 0.1290 & & 0.2142 \\
\hline PB:No Gratitude & -0.1021 & & 0.1387 \\
\hline PB:Animosity & -0.1240 & & 0.1280 \\
\hline T:Time by CG & -0.0095 & & 0.0104 \\
\hline CG:Male & -0.0837 & & 0.0804 \\
\hline CG:Age & 0.0048 & & 0.0036 \\
\hline CG:College or more & -0.2998 & $* * *$ & 0.0782 \\
\hline CG:Family Size & -0.0589 & $* *$ & 0.0258 \\
\hline CG:Owner-Occupied House & -0.1669 & $*$ & 0.1012 \\
\hline CG:log(income) & -0.2525 & $* * *$ & 0.0647 \\
\hline CG:Sleeping Problems & 0.4839 & $* * *$ & 0.0963 \\
\hline Hypertension and Others & 0.2449 & $* *$ & 0.1068 \\
\hline Heart Diseases & 0.0897 & & 0.1856 \\
\hline Diabetes and Others & 0.6967 & $* * *$ & 0.1480 \\
\hline Strokes and Others & 0.2433 & & 0.2927 \\
\hline Gastritis and Others & 0.6211 & $* * *$ & 0.1161 \\
\hline Asthma, Bronchitis & 0.0539 & & 0.1283 \\
\hline Rheumatism & 0.4261 & $* * *$ & 0.0740 \\
\hline Glacoma and Cataract & 0.1438 & & 0.1813 \\
\hline Kidney Diseases & 0.9518 & $* * *$ & 0.2855 \\
\hline Hemorrhoid & -0.1318 & & 0.1160 \\
\hline Alzheimer's & -1.2226 & $* *$ & 0.6202 \\
\hline Depression & 0.9616 & $* * *$ & 0.1176 \\
\hline J-ZBI-8 Score & 0.0560 & $* * *$ & 0.0200 \\
\hline Constant & 0.1293 & & 0.5176 \\
\hline Number of observation & 2,232 & & \\
\hline log likelihood & -1070.9985 & & \\
\hline
\end{tabular}

